\title{
Herpes zoster experience in two pediatric infection clinics
}

\author{
Semra Şen1, Nuri Bayram2, Zümrüt Şahbudak Bal1, Katibe Başak Yıldı1', Mehmet Helvacl2, Fadıl Vardar1 \\ 1 Ege University Medical Faculty, Department of Pediatrics, Infection Clinic, lzmir, Turkey \\ 2Tepecik Education and Research Hospital Pediatric Infection Clinic, Izmir, Turkey
}

\section{Summary}

Aim: Herpes zoster $(\mathrm{HZ})$ is a vesicular cutaneous infection caused by reactivation of the latent varicella-zoster virus from dorsal root ganglia. It is characterized by dermatome distribution. It is usually seen in the elderly and pediatric zoster is rare. In this study we evaluated 16 patients who were admitted to our pediatric clinic and diagnosed as $\mathrm{HZ}$.

Material and Method: Sixteen patients aged between 12 months and 17 years who were admitted to Ege University Medical Faculty Children Hospital and Tepecik Education and Research Hospital Pediatric Infection departments between January 2010 and September 2011 were evaluated retrospectively. Previous varicella disease, varicella vaccination history, existing chronic disease, immunodeficiency, immunosuppressive drug use, trauma, history of operation, history of radiation and presence of stress were questioned.

Results: Nine of 16 patients who were diagnosed as $\mathrm{HZ}$ were female. Three patients had lumbar involvement, six had thoracic involvement, one had disseminated involvement, four had trigeminal involvement, one had cervical involvement and one had sacral involvement. All patients received systemic and local treatment. No complication was observed.

Conclusions: Herpes zoster may be observed in children with or without immune suppression. The disease is benign in healthy children. Complications are rare. (Turk Arch Ped 2013; 48: 40-43)

Key words: Children, herpes zoster, immunsupression

\section{Introduction}

Herpes zoster $(\mathrm{HZ})$ infection occurs as a result of reactivation of the latent varicella zoster virus (VZV) located in the dorsal root ganglia. The disease can develop at any time after the primary infection. In $2 \%$ of the patients exposed to varicella zoster virus prenatally, chickepox develops subclinically and these patients have a risk of development of postnatal $\mathrm{HZ}$ infection (1).

Since the varicella vaccine is an attenuated vaccine, herpes zoster may develop in vaccinated individuals. The risk of development of $\mathrm{HZ}$ after chickenpox is $20-63 / 100$ 000/year. In vaccinated individuals this risk is $14 / 100$ 000/year. Immune deficiency, immunosuppressive treatment and aging increase the risk of $\mathrm{HZ}$ infection. It occurs rarely below the age of ten. The disease involves the cervical and sacral regions in children and lower thoracic region, upper lumbar region and trigeminal nerve in adults. Complications include secondary bacterial infection, depigmentation, development of scar and herpes zoster neuralgia (HZN) (2). In children, eruption, pain and HSN occur more rarely (3). The patients are contagious. In treatment, acyclovir or famcyclovir or valacyclovir may be preferred. In individuals with immunosupression, it may recur and need treatment (2). The aim of this study is to determine the characteristics of $\mathrm{HZ}$ in children with and without immunospression.

\section{Material and Method}

16 patients aged between 12 months and 17 years (mean age $7.3 \pm \mathrm{sd}$ ) who were diagnosed as $\mathrm{HZ}$ infection and hospitalized in pediatric infection clinics in Ege University Medical Faculty and The Ministry of Health Tepecik Education and Research Hospital were examined retrospectively. 9 of the patients $(56.25 \%)$ were hospitalized in the Ministry of Health Tepecik Education and research Hospital and 7 (43.75\%) were hospitalized in Ege University Medical Faculty. Chickenpox history, history of chickenpox vaccination, existing chronic diseases, immune deficiency, use of immunosupressant drugs, 
Table 1. Significant characteristics of the subjects diagnosed as Herpes zoster infection accompanied by chronic disease

\begin{tabular}{|c|c|c|c|c|c|}
\hline Age (years) & Gender & Chronic disease & Vaccination & Dermatome & Hospitalization time (days) \\
\hline 9 & Male & Liver transplantation & None & Thoracic & 4 \\
\hline 11 & Female & Vitiligo & None & Trigeminal & 13 \\
\hline 17 & Male & ALL-2008 & None & Toracic & 9 \\
\hline 4 & Female & Ewing sarcoma & None & Cervical & 4 \\
\hline 13 & Female & Neuroblastoma & None & Lumbar & 9 \\
\hline
\end{tabular}

trauma, operation, history of radiation and presence of stress were interrogated in the patients. The dermatom distribution of the eruptions was determined. The patients were followed up in terms of complications.

\section{Results}

9 of 16 patients who were diagnosed as herpes zoster were female and 7 were male. The female/male ratio was found to be 1.28. Three patients had lumbar, six had thoracic, one had cervical, one had multiple dermatomal, four had trigeminal and one had sacral involvement. All patients received systemic and local treatment. Eight patients (50\%) had a history of chikenpox diagnosed by a physician.

Six of the patients $(32.5 \%)$ had thoracic, four $(25 \%)$ had trigeminal, three had lumbar, one had cervical, one had sacral and one had diffuse eruption (Table 1). When the complaints at the time of presentation were questioned, vesicular eruption was found in 15 patients (93.7\%). Four of these had pain and one had pruritus.

All of the patients had been hospitalized in the ward. Acyclovir treatment was started in all patients intravenously and topically. Supportive treatment (antipruritic, analgesic) was given.

The patients were followed up in terms of complications. Keratitis developed in one of four patients who had trigeminal involvement and soft tissue infection developed in four patients. In the follow-up, pain developed in 11 patients and anelgesia was needed. Pain decreased with paracetamol and ibuprofen in nine patients and with tramadol in two patients. Presence of chronic diseases and malignancy, trauma, use of immunosupressive drugs, history of immune deficiency, surgical intervention and history of stress were interrogated in the patients. No history of immune deficiency, malignancy, use of immunosupressive drug, trauma and surgical intervention was found in the patients. In six patients, a history of stress (emotional, long-term sun exposure) was given as an enhancing factor. In addition, four patients were using immunosupressive drugs because of acute lynphoblastic leukemia, Ewing sarcoma, neuroblastoma and liver transplantation. It was reported that varicella vaccine was administered at the age of 22 months in one patient. No contact with a patient with zona was reported (Table 1 and 2).

When the seasons of infection were evaluated, it was found that seven patients (43.75\%) developed infection in summer, four
Table 2. Significant characteristics of the healthy subjects diagnosed as Herpes zoster infection

\begin{tabular}{|c|c|c|c|c|}
\hline $\begin{array}{l}\text { Age } \\
\text { (years) }\end{array}$ & Gender & Vaccination & Dermatome & $\begin{array}{c}\text { Hospitalization } \\
\text { time (days) }\end{array}$ \\
\hline 4 & Female & None & Trigeminal & 6 \\
\hline 2 & Male & None & Trigeminal & 5 \\
\hline 4 & Female & $(+)$ & Thoracic & 10 \\
\hline 9 & Female & None & Sacral & 9 \\
\hline 3 & Female & None & Thoracic & 6 \\
\hline 10 & Female & None & Lomber & 10 \\
\hline 3 & Famele & None & Torakal & 9 \\
\hline 2 & Male & None & Lumbar & 10 \\
\hline 1 & Male & None & Diffuse & 4 \\
\hline 8 & Male & None & Thoracic & 4 \\
\hline 17 & Femal & None & Trigeminal & 9 \\
\hline
\end{tabular}

(25\%) developed infection in fall, three (18.75\%) developed infection in spring and two (12.5\%) developed infection in winter.

Vesicules developed on the back in six (37.5\%) of the patients with zona, in the eye in four (25\%), on the abdomen in three $(18.75 \%)$, on the extremity in one $(6.25 \%)$, on the neck in one $(6.25 \%)$, on the hip in one $(6.25 \%)$ and dissemination was found in one patient. 15 patients had unilateral involvement.

The mean leukocyte count of the patients was found to be $7740 \mathrm{~mm}^{3}$ (the least-the higest: $1310-16800 \mathrm{~mm}^{3}$ ), the mean lymphocyte count was found to be $3779 \mathrm{~mm}^{3}$ (the least-the higherst: 330-10400), the mean neutrophil count was found to be 3230 (the least-the highest: $840-4500 \mathrm{~mm}^{3}$ ). Lymphopenia $\left(<2000 \mathrm{~mm}^{3}\right)$ was found in six patients. The mean time of eruption was 6 days (the least-th highest: 4-13). Fever was observed only in the patient with keratitis. In addition, lymphopenia $\left(170 \mathrm{~mm}^{3}\right)$ and a history of vitiligo were reported in the same patient.

The mean time of hospitalization was 7.31 days (the least-the highest: 4-13) in all patients, 8.3 days in patients with eye involvement and 5.7 days in patients who used immunosupressive drugs or who had malignancy. The mean time of acyclovir treatment was found to be 8,06 days (the least-the 
highest: 4-14). Two patients switched to oral consecutive valacyclovir treatment. No side effect related to acyclovir was observed.

\section{Discussion}

Herpes zoster infection typically occurs in adults $(4,5)$. While chickenpox is usually observed in children aged 5-9 years, $\mathrm{HZ}$ infection usually occurs in people above the age of 50 years. While the frequency of $\mathrm{HZ}$ infection is $0,45 / 1000 /$ year in children aged 0-14 years, it is 4.2-4.5/1000 people/year in individuals above the age of 75 years $(4,5)$. The majority of patients who have $\mathrm{HZ}$ in the childhood are above the age of 5 and a great part of these patients have a history of in utero chickenpox or chickenpox below the age of one or a history of exposure to chickenpox $(4,5)$. In our study, the age of the patients diagnosed as $\mathrm{HZ}$ infection ranged between 12 months and 17 years (mean: 7.3 years) which was compatible with the literature (6). In a study performed in Japan, it was reported that $\mathrm{HZ}$ infection showed a peak at the age of 4-5 and 10-11 years in children with a normal immune system. The female/male ratio was found to be near to 1 and compatible with the literature (6).

Studies have reported that $\mathrm{HZ}$ infection can develop at a young age in children exposed to varicella zoster virus prenatally or in the first year of life (6). One of our patients was 12 months old and it was reported he did not have chickenpox. In a study performed by Kurlan et al. (6), development of $\mathrm{HZ}$ infection was reported in patients aged four months old and seven months old. It was reported that these patients had contact with people with chickenpox during the newborn period and presented with $\mathrm{HZ}$ infection without having chickenpox themselves. This was explained with inadequate cellular immune response due to immature immune system.

One of the characteristics of Herpes zoster infection is presence of pain before development of eruption and presence of pain in that dermatome after development of eruption. However, pain is less severe and less frequent in $\mathrm{HZ}$ infection in the childhood. Different views about pain which develops during infection have been reported. Although the rate of pain was low in our study, some publications have reported a rate of $40 \%$ (6).

The virus most frequently affects the dermatomes between T3 and L3 (thoracic 75\%, lumbar 11\%). In some studies, a high rate of trigeminal involvement has been reported $(4,5,6,7)$. Thoracic involvement was found in 6 of our patients (32.5\%), trigeminal involvement was found in four (25\%) and lumbar involvement was found in three (18.75\%). Extensive dermatomal involvement was found in one patient.

It is known that virus specific cellular immunity is important in controlling of viral activation and dissemination. Therefore, VZV infection may have a more severe course in individuals with supressed immunity. In hematologic malignancies, cellular immunity is damaged in two ways by the effects of both the malignancy itself and the chemotherapeuticals. Other risk factors reported include other malignancies, HIV infection, organ transplantation, trauma, chronic steroid usage, immunosupressive therapies, chronic renal failure and chronic respiratory problems. Cronic psychological stress has been reported to decrease cellular immunity response and thus enhance development of $\mathrm{HZ}$ infection $(6,8,9,10)$. Use of immunosupresant (tacrolimus) because of acute lymphoblastic leukemia, Ewing sarcoma, neuroblastoma and liver transplantation was present in our patients. The ages at the time of chickenpox could not be calculated, since they were not reported in medical history.

Postherpetic neuralgia is the most common complication. Its cause is not known. Its possiblity increases as the age gets older. It is observed 1-6 months after HZ infection (6,7). HSN did not develop in our patients. HSN was not observed in the patient group consisting of 15 patients studied in Turkey. In addition, it was observed in only one patient with no immune deficiency in a series consisting of 244 patients $(6,7)$. Complications including motor weakness and visceral involvement may occur, though rarely. No complication was observed in our patient which was compatible with the literature. Complications occur more frequently in patients with immune deficiency; multiple dermatomes are involved and hemorrhagic vesicles may be observed. Absence of such cases in our study may be related with the low number of patients.

The cranial nerves are involved in $10-15 \%$ of the children with herpes zoster infection and opthalmic signs (konjonktivits, ulcerative keratitis, uveitis etc.) are present in $50 \%$ of the patients with involvement of the trigeminal nevre. Ophtalmic complications are observed especially when vesicular lesions are extended to the tip of the nose. $\mathrm{HZ}$ lesions appear unilaterally on the forehead, palpebrae and scalp. In addition, vesicles are observed on the sides and tip of the nose and this is called as Hutchinson sign. Damage to the nerve, ocular and orbital tissues results from chronic inflammation or directly from viral infection. This was found in one of our four patients who had opthalmic involvement. All patients had conjunctival hyperemia and this was limited with the frontal dermatome. It was stated that the orbital movements were painful at presentation and corneal sensitivity was found. It was stated that none of the patients was vaccinated. No permanent sequela occured in the long-term. Absence of sequela may be explained by the low number of patients or timely administration of intravenous acyclovir and supportive treatment $(4,5,11)$. Interestingly, the mean hospitalization time of this group (7.31 days) was found to be longer compared to the immunocompromized patients (5.7 days). It was thought that this difference might be explained by the inadequate number of patients.

The disease is rarely observed in healthy children and usually recovers without complication. In some studies, complications including aseptic meningitis, extension of the eruption and facial palsy have been reported in healthy children (4). It is generally accepted that the disease recovers in 1-3 weeks without complication, antiviral treatment is not needed and supportive treatment is adequate. However, antiviral treatment is recommended in presence of acute zoster pain, cranial nevre involvement, disseminated zoster infection, hereditary or acquired immune deficiencies and atopic dermatitis. Antiviral drugs used in $\mathrm{HZ}$ treatment in adults include acyclovir, 
valacyclovir, famcyclovir and brivudine. In our country, acyclovir and valacyclovir have been approved for use in the childhood. It has been reported that early antiviral treatment decreases the disease time and pain after zoster infection (4).

The treatment period is seven days or until 2 days later after new lesion appearance stops. Our patients recovered with acyclovir and supportive treatment without permanent sequelas (4). If acyclovir is started 72 hours after the signs begin, it speeds recovery and decreases pain (5).

Conclusively, $\mathrm{HZ}$ infection is generally observed in children who receive chemotherapy or who have immune deficiency, though it may rarely occur in healthy children. Trigeminal involvement is considerably rare in children and generally has a benign course. Acyclovir (30 mg/kg/day, 3 doses, intravenous) and supportive therapy are adequate in treatment (4).

$\mathrm{HZ}$ infection may recur especially in immunocompromized patients $(1-4 \%)$. No recurrence was observed in the follow-up in our patients $(12,13,14)$.

Vaccination was reported only in one of our patients, because this vaccine is not included in the vaccination schedule of the Ministry of Health. However, detailed studies are needed for this subject. The superiority of vaccination is that a weaker strain is latent instead of a wild strain. This is especially important with the increased risk of $\mathrm{HZ}$ infection in adult transplantation cases $(11,15)$.

Conclusively, $\mathrm{HZ}$ infections may be observed in healthy children, though it occurs more frequently in immunocompromized children. In children, treatment is recommended to prevent dissemination in immunocompromized ones and to prevent development of keratitis in trigeminal involvement. It has a benign prognosis in patients with a normal immune system. Since herpes zoster infection occurs rarely in children, the patient numbers are generally low in studies. More studies are needed in terms of disease and treatment approaches.

\section{Conflict of interest: None declared.}

\section{References}

1. Sauve RS, Leung AK. Congenital varicella syndrome with colonic atresias. Clin Pediatr (Phila) 2003; 42(5): 451-453.

2. Leung AK, Robson WL, Leong AG. Herpes zoster in childhood. J Pediatr Health Care 2006; 20(5): 300-303.

3. Teran CG, Villarroel P, Teran-Escalera CN. Herpes zoster in healthy children. Int J Infect Dis 2008; 12(6): e159-160.

4. Kökçam I, Dilek N. Sağlıklı iki çocukta herpes zoster. J Dermatol 2009; 3: 19-21.

5. Ulusoy S, Leblebicioğlu H. Viral enfeksiyonlar. Bilimsel Tıp Yayınevi. 2011; 181-207.

6. Yalaki Z, Öztürk A, Taşar MA, Dallar Y. Sağlıklı çocuklarda herpes zoster enfeksiyonu. Çocuk Enf Derg 2010; 4: 96-99.

7. Rahşan M, Evans ES, Şahin S. Çocukluk çağı herpes zoster enfeksiyonu: 15 vakalık retrospektif bir çalışma. Türkiye Klinikleri J Dermatol 2005; 15: 121-124.

8. Weinberg JM. Herpes zoster: epidemiology, natural history and common complications. J Am Acad Dermatol 2007; 57(Suppl 6): S130-135.

9. Çelik Ü, Alhan E, Aksaray N, Kocabaş E, Alabaz D, Dede T, Bayram I, Leblebisatan G. Malignensili çocuklarda varisella-zoster virüs enfeksiyonu. Çocuk Enf Derg 2008; 3: 105-8.

10. McDonald JR, Zeringue AL, Caplan L, Ranganathan P, Xian H, Burroughs TE, Fraser VJ, Cunningham F, Eisen SA. Herpes zoster risk factors in a national cohort of veterans with rheumatoid arthritis. Clin Infect Dis 2009; 48(10): 1364-1371.

11. De Freitas D, Martins EN, Adan C, Alvarenga LS, Pavan-Langston D. Herpes zoster ophthalmicus in otherwise healthy children. Am J Ophthamol 2006; 142(3): 393-399.

12. Straus SE, Ostrove JM, Inchauspé G, Felser JM, Freifeld A, Croen KD, Sawyer MH. NIH Conference. Varicella-zoster virus infections. Biology, natural history, treatment, and prevention. Ann Intern Med 1988; 108(2): 221-237.

13. Donahue JG, Choo PW, Manson JE, Platt R. The incidence of herpes zoster. Arch Intern Med 1995; 155(15): 1605-1609.

14. Yawn BP, Saddier P, Wollan PC, St Sauver JL, Kurland MJ, Sy LS. A population-based study of the incidence and complication rates of herpes zoster before zoster vaccine introduction. Mayo Clin Proc 2007; 82(11): 1341-1349.

15. Arness T, Pedersen R, Dierkhising R, Kremers W, Patel R. Varicella zoster virus-associated disease in adult kidney transplant recipients: incidence and risk-factor analysis. Transpl Infect Dis 2008; 10(4): 260-268. 